\title{
The Application of the Correlative Analysis and the Regression Function for Determining Correlations of the Measurement Results of Acoustic Emission Generated by Partial Discharges
}

\author{
T. BOCZAR* AND P. FRĄCZ \\ Faculty of Electrical Engineering, Automatic Control and Computer Science \\ Opole University of Technology, Mikołajczyka 5, 45-271 Opole, Poland
}

\begin{abstract}
The subject matter of this paper is connected with development of the assessment methods of results obtained at measurements of partial discharges occurring in insulation systems of power transformers using the acoustic emission method. The paper presents the results connected with determining correlation between partial discharge generation voltage and selected descriptors characterizing the emitted signals of acoustic emission in the frequency domain. Authors use the selected descriptors as comparative criteria for recognition of the basic partial discharge forms that may occur in paper-oil insulation of power transformers. The correlation coefficient and regression function were used to determine the correlation degree between the variables under study.
\end{abstract}

PACS numbers: 43.58.-e, 43.60.-c, 43.60.Bf

\section{Introduction}

The paper describes the dependence between the changes of the voltage supplying the spark-gap modeling partial discharges (PDs) on indeterminate potential particles moving in insulation oil and the values of selected descriptors calculated for the amplitude spectrum of the acoustic emission (AE) pulses generated [1-10]. It is a simple type relation, which is characteristic of a unilateral influence of the cause, which is the voltage changes, on the result, which are the value changes of the descriptors under study. In the index case the two features are measurable, and the voltage value of $\mathrm{PD}$ generation is an independent variable, i.e. interpreting $X$, and the value of a given descriptor is a dependent variable $Y$, i.e. being interpreted. A correlation coefficient and regression function were used in order to determine the degree of dependence between the variables under study. The spark-gaps modeling basic PD forms, the way of measurement taking and analysis of the acoustic emission signals generated by them have been characterized in detail in papers $[1,2]$. The measurements were taken and the analysis of the $\mathrm{AE}$ pulses generated at the voltage changes in the range from $60 \%$ to $80 \%$ of the system breakdown voltage value was carried out with gradation every $5 \%$.

For frequency spectra the values of the following descriptors were determined: shape and peak coefficients,

\footnotetext{
* corresponding author; e-mail: t.boczar@gmail.com
}

mediumistic frequency and frequency for the highest value in the spectrum, maximum, mean and root-mean-square values, which were calculated for the positive and negative voltage polarizations separately [2].

\section{The application of tests of significance for the analyses of the correlation coefficient and regression function}

A graphic method, consisting in drawing point (correlative) diagrams was used to find out initially whether there is correlation between the characteristics under study.

Figures 1 and 2 show point diagrams obtained at supplying voltage changes for the mean (Fig. 1) and root-mean-square (RMS) (Fig. 2) values. Based on the diagrams obtained, a linear dependence between the voltage changes and the descriptor values investigated was observed. Therefore the Pearson - $\rho$ linear correlation coefficient, which is the best criterion for determining the relation strength between two linearly dependent measurable characteristics, was used for further assessment of the correlative dependence. Pearson linear correlation coefficient may be determined using formula (1), through standardization of covariance, which is an arithmetic mean of deviation product of $X$ and $Y$ variable values from their arithmetic means

$$
\rho=\frac{\operatorname{cov}(X, Y)}{s_{x} s_{y}},
$$

where $\operatorname{cov}(X, Y)$ - covariance of variables $X$ and $Y$, 


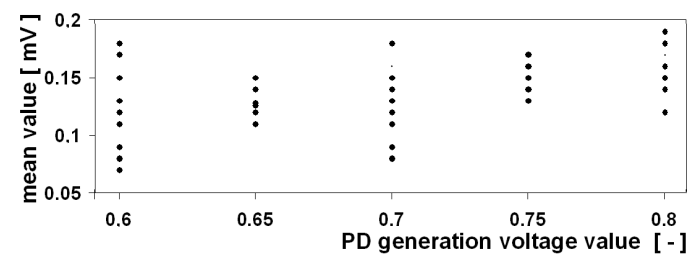

Fig. 1. Correlative diagram of the PD generation voltage value and the mean values calculated for the $\mathrm{AE}$ pulses generated by PDs on indeterminate potential particles at the positive voltage polarization.

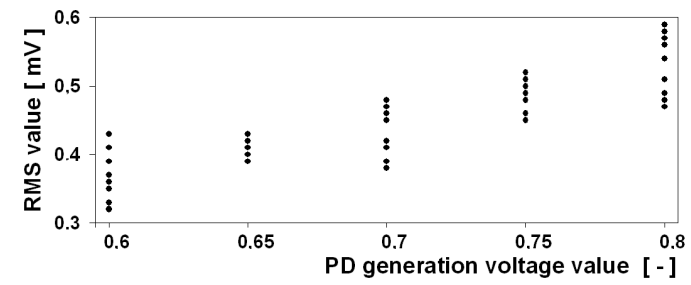

Fig. 2. Correlative diagram of the PD generation voltage value and the RMS values calculated for the AE pulses generated by PDs on indeterminate potential particles at the positive voltage polarization.

$s_{x}$ - standard deviation of variable $X, s_{y}$ - standard deviation of variable $Y$ [2].

A test of significance of Pearson linear correlation coefficient was used to find out whether the characteristics under study are correlated, in which $t$-Student distribution and statistics were used for not too numerous tests

$$
t=\frac{r}{\sqrt{1-r^{2}}} \sqrt{n-2}
$$

where $t$ - statistics, $n-$ number of tests, $r$ - correlation coefficient estimator $\rho[2]$.

To investigate the significance of the correlation coefficient the values of structural coefficients of the regression function, which ascribes specific values of independent variables to mean values of a dependent variable in an analytical manner were determined, the equation of which can be expressed by dependence

$$
y=\alpha x+\beta,
$$

where $\alpha, \beta$ - structural parameters of the linear regression function of dependent variable $y$ in relation to independent variable $x[2]$.

In order to estimate numerical values of structural parameters of a linear regression function of the variable representing the selected descriptor changes in relation to the variable corresponding to $\mathrm{PD}$ voltage generation changes, the estimation of these parameters was applied using the least squares method and the test of significance based on $t$-Student distribution.

\section{Results of the statistical analyses carried out}

The results of the statistical tests carried out are presented in Table. Lack of correlation or its presence be- tween PD generation voltage changes and the descriptor values calculated were determined based on the test of significance results of the linear regression function coefficient. Moreover, Figs. 3-9 show the runs of the linear regression function calculated for the particular descriptors with marked uncertainty intervals for each measurement point separately, for the AE pulses generated in the positive voltage half-time at $\mathrm{PD}$ generation voltage changes. The results obtained for the negative voltage polarization and for other basic PD forms under study have been presented in the monograph [2].

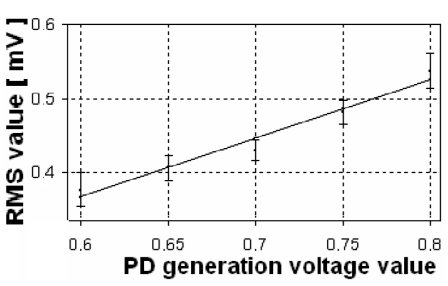

Fig. 3. Regression function determined for the amplitude spectrum of the $\mathrm{AE}$ pulses generated by $\mathrm{PDs}$ on indeterminate potential particles at the positive voltage polarization for the RMS value in the voltage change function.

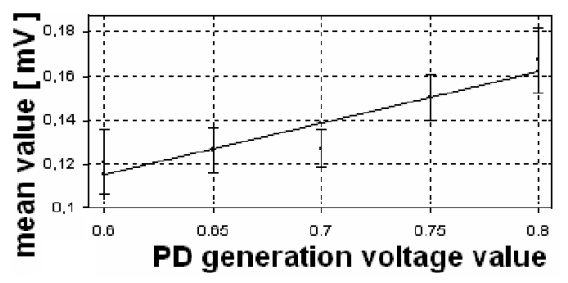

Fig. 4. Regression function determined for the amplitude spectrum of the $\mathrm{AE}$ pulses generated by $\mathrm{PDs}$ on indeterminate potential particles at the positive voltage polarization for the mean value in the voltage change function.

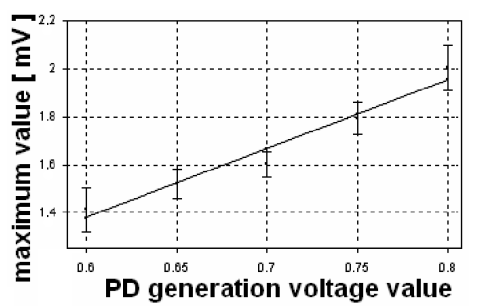

Fig. 5. Regression function determined for the amplitude spectrum of the AE pulses generated by PDs on indeterminate potential particles at the positive voltage polarization for the maximum value in the voltage change function. 


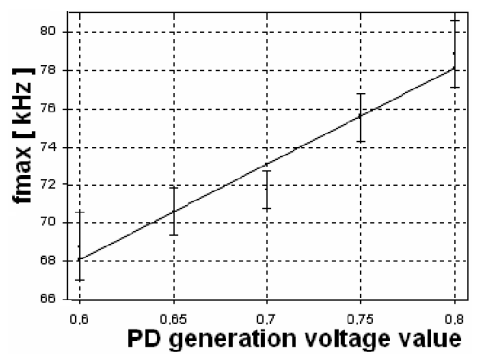

Fig. 6. Regression function determined for the amplitude spectrum of the AE pulses generated by PDs on indeterminate potential particles at the positive voltage polarization for the frequency for the maximum value in the voltage change function.

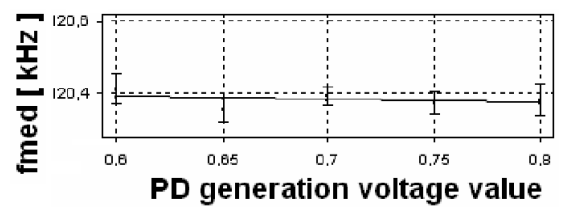

Fig. 7. Regression function determined for the amplitude spectrum of the AE pulses generated by PDs on indeterminate potential particles at the positive voltage polarization for the median frequency in the voltage change function.

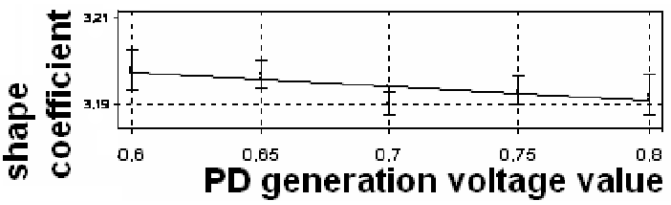

Fig. 8. Regression function determined for the amplitude spectrum of the AE pulses generated by PDs on indeterminate potential particles at the positive voltage polarization for the shape coefficient in the voltage change function.

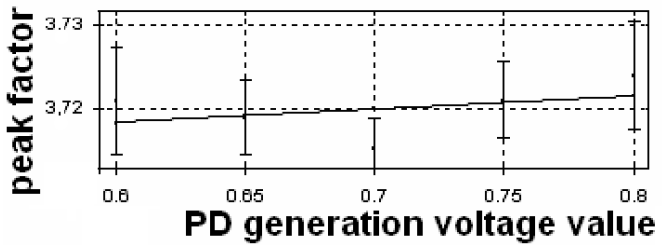

Fig. 9. Regression function determined for the amplitude spectrum of the AE pulses generated by PDs on indeterminate potential particles at the positive voltage polarization for the peak factor in the voltage change function.

TABLE

Coefficient values of linear regression, correlation and the test of significance values for the regression coefficient determined for the AE pulses generated by PDs on indeterminate potential particles at the positive voltage polarization for the selected descriptors at the supplying voltage changes.

\begin{tabular}{|c|c|c|c|c|c|c|}
\hline \multirow[t]{2}{*}{ Descriptor } & \multicolumn{2}{|c|}{$\begin{array}{c}\text { Linear regression } \\
\text { coefficients }\end{array}$} & \multirow[t]{2}{*}{$\begin{array}{l}\text { Correlation } \\
\text { coefficients }\end{array}$} & \multicolumn{3}{|c|}{$\begin{array}{c}\text { Significance assessment of the } \\
\text { regression coefficient }\end{array}$} \\
\hline & $a$ & $b$ & & $t$ & $t_{\alpha}$ & Correlation \\
\hline RMS value $[\mathrm{mV}]$ & 0.794 & -0.109 & 0.984 & 9.714 & & yes \\
\hline mean value $[\mathrm{mV}]$ & 0.230 & -0.024 & 0.935 & 4.564 & & yes \\
\hline maximum value $[\mathrm{mV}]$ & 2.914 & -0.373 & 0.982 & 8.981 & & yes \\
\hline median frequency $f_{\text {med }}[\mathrm{kHz}]$ & -0.080 & 120.4 & -0.283 & -0.507 & 2.253 & no \\
\hline $\begin{array}{c}\text { frequency for the maximum } \\
\text { value } f_{\max }[\mathrm{kHz}]\end{array}$ & 50.3 & 37.9 & 0.979 & 8.261 & & yes \\
\hline shape coefficient [-] & -0.032 & 3.216 & -0.746 & -1.940 & & no \\
\hline peak factor [-] & 0.016 & 3.4 & 0.381 & 0.714 & & no \\
\hline
\end{tabular}

\section{Summary}

Investigating the influence of generation voltage changes on descriptor values characterizing the AE signals generated by PDs in the frequency domain, a strong correlation dependence for both polarizations, at the correlation coefficient higher than 0.93 , for maximum, mean and rms values and frequency for the maximum value in a spectrum was observed. This dependence was confirmed with a $10 \%$ error margin based on the results of the analysis test of coefficient significance of the linear regression function. Based on the significance test results and on the regression function runs, lack of correlative dependence between shape and peak coefficients, median 
frequency and the value of $\mathrm{PD}$ generation voltage was demonstrated. Thereby the usefulness of the assumed descriptors for basic PD form recognition was confirmed as their values do not depend on voltage changes supplying the spark-gaps under study. The procedure presented in this paper, which makes it possible to determine correlation of two variables belonging to the same statistical population, may be used for other processes dealing with cause-result relation.

\section{Acknowledgments}

The research work has been financed with the means assigned for science as research-development project No. R01 00601.

\section{References}

[1] T. Boczar, IEEE Trans. Diel. Electr. Insulat. 8, 598 (2001).

[2] T. Boczar, Objectivization of results obatained by means of acoustical method of incomplite electrical discharges investigations for application statictical and digital processing procedures, Studies and Monographs, No. 147, Oficyna Politechniki Opolskiej, Opole 2003 (in Polish).
[3] F. Witos, Z. Gacek, Z. Opilski, Acta Phys. Pol. A 114, A-249 (2008).

[4] T. Boczar, S. Borucki, A. Cichon, M. Lorenc, Acta Phys. Pol. A 114, A-21 (2008).

[5] F. Witos, Z. Gacek, P. Paduch, Mol. Quant. Acoust. 28, 271 (2007).

[6] T. Boczar, M. Szmechta, D. Zmarzły, Mol. Quant. Acoust. 28, 39 (2007).

[7] A. Szpakowski, C. Tyszkiewicz, T. Pustelny, Acta Phys. Pol. A 114, A-237 (2008).

[8] T. Boczar, S. Borucki, A. Cichon, Mol. Quant. Acoust. 28, 13 (2007).

[9] T. Boczar, D. Zmarzły, IEEE Trans. Dielectr. Electr. Insulat. 11, 433 (2004).

[10] T. Boczar, S. Borucki, A. Cichon, D. Zmarzły, IEEE Trans. Dielectr. Electr. Insulat. 16, 214 (2009). 